\title{
Experimental Study on Innovative Slip Form Method for the Construction of Tapered Concrete Pylon of Long-Span Cable Bridge
}

\author{
Hee Seok Kim, Young Jin Kim, Won Jong Chin, Hyejin Yoon \\ Structural Engineering Research Division, Korea Institute of Civil Engineering and Building Technology, \\ Goyang-si, South Korea \\ Email: lagoon@kict.re.kr
}

Received 6 July 2014; revised 10 August 2014; accepted 18 August 2014

Copyright (C) 2014 by authors and Scientific Research Publishing Inc.

This work is licensed under the Creative Commons Attribution International License (CC BY). http://creativecommons.org/licenses/by/4.0/

c) (i) Open Access

\begin{abstract}
The construction of the three-dimensionally shaped pylons higher than $400 \mathrm{~m}$ requires a very high technological degree. It is known that the application of the tapered slip form method for the erection of the concrete pylon of long-span cable bridges offers the advantage of being significantly faster than applying the auto-climbing system (ACS) form method. Therefore, this study presents the development of an innovative slip form system for pylons with tapered cross-section. Surface wave inspection system is applied for the determination of slip-up time, wireless hydraulic control system is applied for auto rising, GPS system is used to manage the pylon configuration, and lightweight GFRP (Grass Fiber Reinforced Plastic) panels are applied in the slip form system. Small-scale tests were conducted three times to validate the performance of the developed core technologies, and full-scale tests were conducted twice to validate and verify the developed innovative slip form. The full-scale tapered concrete pylons have hollow shafts and a height of $10 \mathrm{~m}$. The sectional dimensions are varied according to the construction height. The experimental constructions of the tapered pylons using the innovative slip form were conducted successfully. This system is the world's first application of GFRP slip form panel.
\end{abstract}

\section{Keywords}

Slip Form System, Surface Wave Inspection System, Wireless Hydraulic Control System, Pylon Configuration, Lightweight GFRP Panel

\section{Introduction}

The moving form systems mostly adopted for the erection of the concrete pylons of super long-span bridges are

How to cite this paper: Kim, H.S., Kim, Y.J., Chin, W.J. and Yoon, H. (2014) Experimental Study on Innovative Slip Form Method for the Construction of Tapered Concrete Pylon of Long-Span Cable Bridge. Engineering, 6, 633-643.

http://dx.doi.org/10.4236/eng.2014.610063 
the ACS (Auto Climbing form System) and the slip form system, which differ in their operational methods. Slip forming places concrete continuously by lifting vertically the form panels and yoke leg geared with a vertical jack attached to a rod embedded in the concrete mass. Since slip forming proceeds through the repetition of 5 simultaneous tasks including the assemblage of form, the assemblage of reinforcement, the placing of concrete, the curing and the removal of form, this method presents the advantage of shortening significantly the construction period compared to other methods even when considering the periods devoted to the installation and dismantlement. Especially, slip forming is at least twice faster than the ACS method by placing a height of concrete of 2 to $4 \mathrm{~m}$ per day. It also provides high quality and monolithic construction thanks to the continuous placing without construction joint. Therefore, slip forming enables to minimize the occurrence of micro-cracks that can be frequently observed in common concrete structures.

The tapered slip form system is mainly applied for the erection of high pylons necessitating extremely complex construction technology since the cross section varies with respect to the height and the shape of the pylon changes three-dimensionally. It is generally applied in the erection of the high pylons of super long-span bridges like cable stayed bridges and suspension bridges. However, despite of the vast experience gathered in the numerous long-span bridge construction sites in Korea, the design, fabrication and operation of the tapered slip form system are still completely relying on several foreign specialized companies, which let us use a subordinate technology resulting in tremendous outflow of foreign currency for the erection of high pylons. Accordingly, the acquisition of the self-reliant and domestic tapered slip form system integrating automation technology will contribute to our competitiveness in winning foreign construction projects as well as prevent the outflow of our national wealth [1].

In this research, efforts were endeavored to contribute to the modularization and weight reduction of the system so as to ease the assemblage, installation and dismantlement of the components of the slip form system. By integrating the automated system operation technology and the accurate high pylon configuration control technology, the construction period can be drastically shortened. The developed tapered slip form system provides an advanced system also securing easy quality control. A series of 3 mockup tests of the slip form system verified the performance of each individual core technology, and a series of two public validation tests enabled to verify and improve the performance of the developed system.

\section{Development of Tapered Slip Form System}

The tapered slip form system developed in this research (Figure 1) is constituted by the system design and fabrication technology, the lightweight form system design and fabrication technology, the slip form system

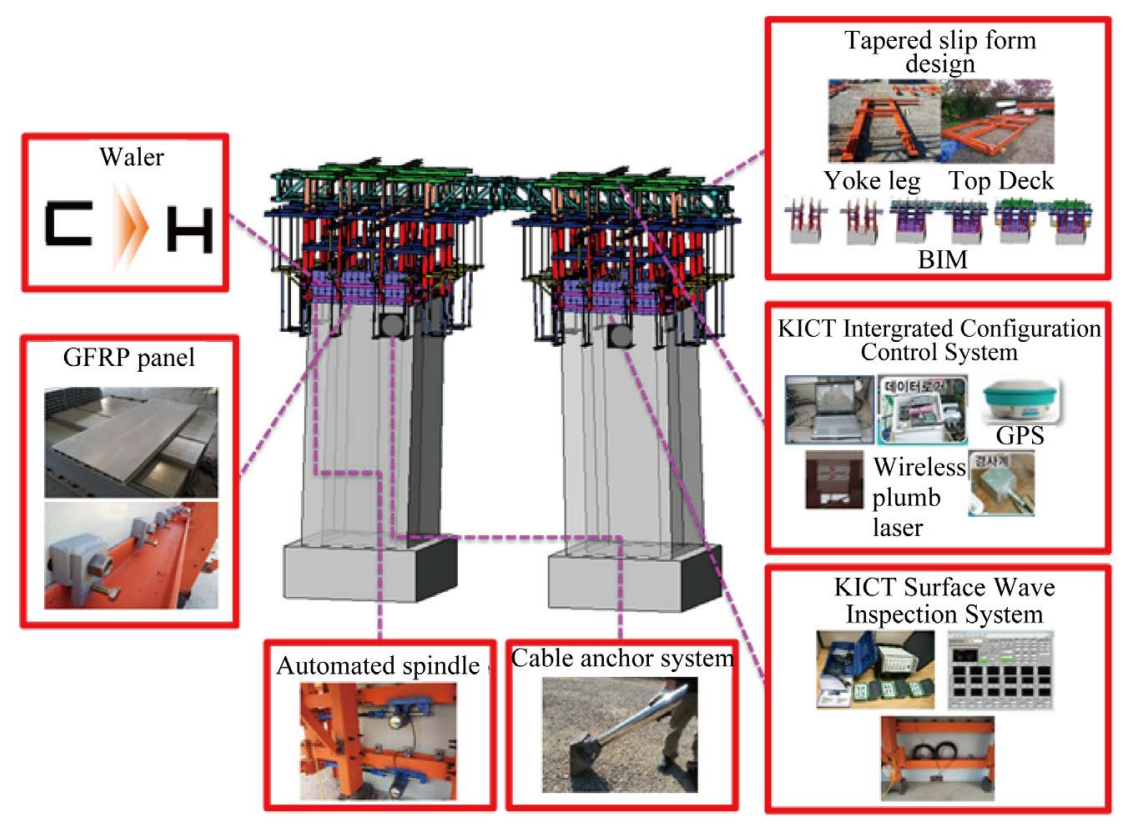

Figure 1. The developed tapered slip form system. 
automation technology, and the slip form positioning and high pylon configuration control technology (Table 1). Table 1 shows the summary of the technology developed by this study. These technologies enhance drastically the performances of the tapered slip form system by supplementing and improving the problems encountered in previous technologies.

\subsection{Design of Tapered Slip Form System}

In view of its scale and symbolism, the pylon is the most distinctive structure among the components of the super long span-bridge. Accordingly, the localization of the design and fabrication technology of the tapered slip form system, known as the latest erection method of the pylon, can be considered as a critical factor in term of the establishment of the self-reliant construction of super long span-bridge.

This research developed the design and fabrication technology of the slip form system enabling to cope with the tapered configuration of the cross section varying from the base of the pylon to its top. First, the height and shape of the pylon were determined and, the preliminary design of the components of the slip form system was conducted considering the adaptation to the tapered shape. Thereafter, the structural stability of the slip form system was verified using the commercial program Midas prior to the detailed design and drawings of the details. Moreover, the design results were examined visually by BIM to minimize the construction errors induced by the two-dimensional drawings. The virtual assemblage and construction enabled to verify in advance the practicability of the developed slip form system (Figure 2 and Figure 3) [2].

\subsection{Lightening of Tapered Slip Form System}

The traditional steel form relies on manpower and equipment for the assemblage, dismantlement and transport of the members. This means that long time is spent for the assemblage and dismantlement. In addition, very costly crane equipment must be mobilized because of the weight of the steel form. In order to solve these prob-

Table 1. Comparison between the developed and existing technologies.

\begin{tabular}{|c|c|c|c|}
\hline \multicolumn{2}{|c|}{ Core technology of slip form system } & Previous technology & Technology developed in this study \\
\hline \multicolumn{2}{|c|}{ Design of tapered slip form system } & $\begin{array}{l}\text { Design of tapered slip form system } \\
\text { (existing technology) }\end{array}$ & $\begin{array}{l}\text { Improved design of tapered slip form system } \\
\text { (application of BIM technology) }\end{array}$ \\
\hline \multicolumn{2}{|c|}{ Lightweight tapered slip form system } & Steel form & Modular GFRP form \\
\hline \multirow{3}{*}{$\begin{array}{l}\text { Automation of } \\
\text { tapered slip form } \\
\text { system }\end{array}$} & $\begin{array}{l}\text { Determination of } \\
\text { slip-up time }\end{array}$ & Traditional method using probing rod & $\begin{array}{l}\text { Quantitative method applying surface wave } \\
\text { inspection system }\end{array}$ \\
\hline & Hydraulic system & Manual hydraulic control & Automated wireless hydraulic control \\
\hline & Spindle control & Manpowered & Automated electro-motor \\
\hline \multicolumn{2}{|c|}{ Erection accuracy control } & $\begin{array}{c}\text { Electro-optical wave station, plumb } \\
\text { laser }\end{array}$ & $\begin{array}{l}\text { Wireless remote verticality control (GPS, inclinometer, } \\
\text { image-transmitting plumb laser) }\end{array}$ \\
\hline
\end{tabular}
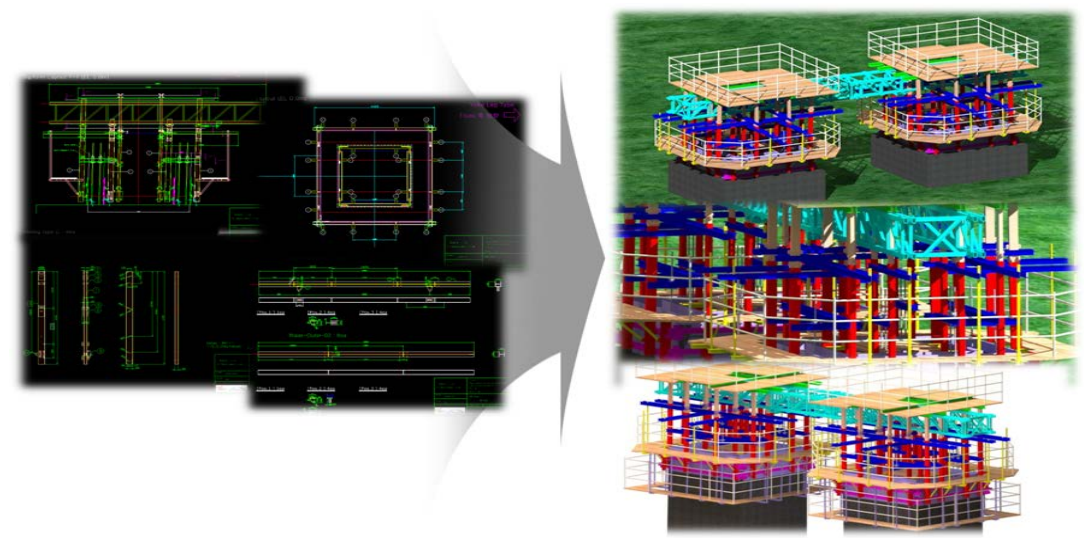

Figure 2. Tapered slip form system for the erection of the 2 legs of the pylon (BIM). 


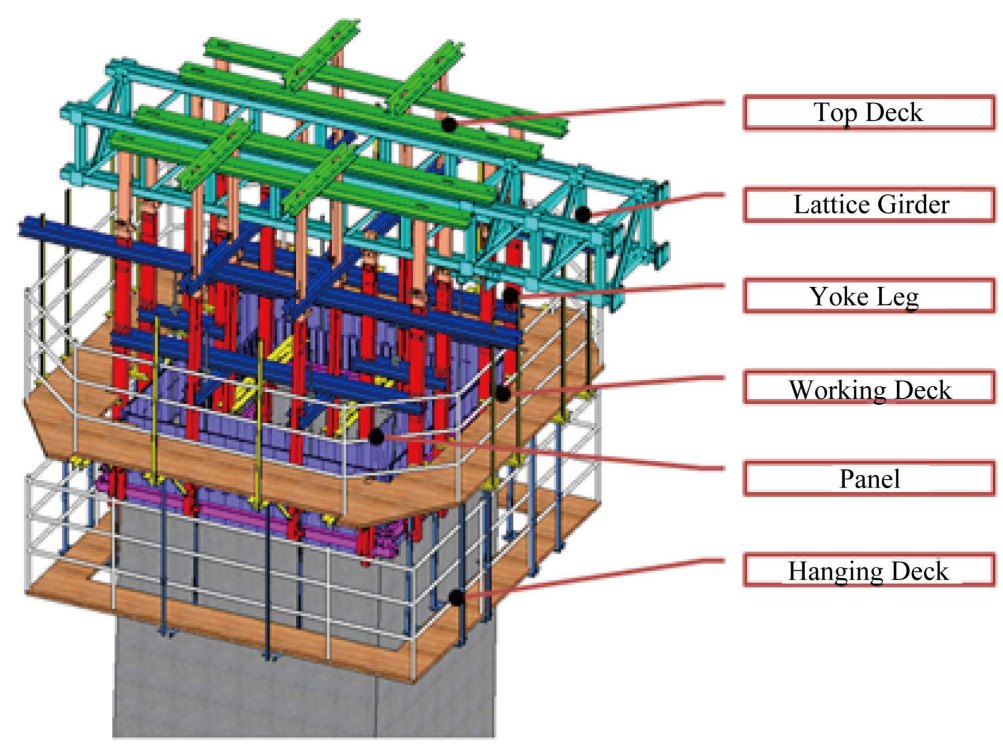

Figure 3. Composition of the slip form system.

lems, modular lightweight GFRP forms were developed for the first time in the world and applied to the slip form system. The GFRP form plays not only the role of form for the placing of concrete but also contributes structurally as a tension stiffener in the whole system. Furthermore, the steel form is vulnerable to damages caused by salt attack in marine environment, which induces increased costs for the quality control of the system. Besides, the GFRP form can supplement this disadvantage and can secure stable quality of concrete owing to its insulating capacity in winter [3].

If such modular GFRP form is applied as component of the slip form system (Figure 4), the weight of the system can be reduced and its installation, operation and removal improved. The quality control of concrete will also be facilitated. Accordingly, such enhanced system will enable very efficient erection of the pylon.

\subsection{Automation of Tapered Slip Form System}

The slip-up of the slip form system shall be executed at the time at which concrete becomes able to be selfsupported when removing the form and to develop sufficient strength in a long term. Slip-up shall also be conducted before the bond between concrete and the form becomes so strong that excessive jacking force is required to lift the form.

The technique using surface wave velocity exploits the characteristics of the surface wave propagating along the surface. The variation of the surface wave velocity indicates the extent of hardening of concrete. This research measures the extent of hardening of concrete using the surface wave velocity. This quantitative measurement enables to determine the optimal slip-up time of the slip form. Therefore, an ultrasonic module (Figure 5) is bonded to the lightweight GFRP form for real time measurement of the ultrasonic wave signal in concrete. A surface wave inspection system (KSWIS: KICT Surface Wave Inspection System) was developed for the first time in the world to analyze the surface wave velocity from the measured ultrasonic wave signal (Figure 6). This system was designed to evaluate quantitatively and continuously the extent of hardening of concrete and, determine the slip-up time of the slip form system [4] [5].

The slip-up of the slip form system is done by means of hydraulic jacks along a rod embedded in the concrete mass. The erection of the concrete pylon mobilizes dozens of hydraulic jacks. Attention should thus be paid to avoid the occurrence of eccentricity during the slip-up. Therefore, each hydraulic jack must be controlled appropriately. This research developed an automated hydraulic system enabling to execute accurately the lifting and descent of the hydraulic jacks. This system linked to a control PC in a remote control room makes it possible to control wirelessly the hydraulic jacks and achieve more accurate configuration control.

The tapering of the slip form system is executed by means of a mechanical device called spindle. The rotation of the spindle was performed by the technician operating the slip form system using a spanner fabricated to fit with the size of the spindle. This means that the tapering of the slip form system must be completed within the 

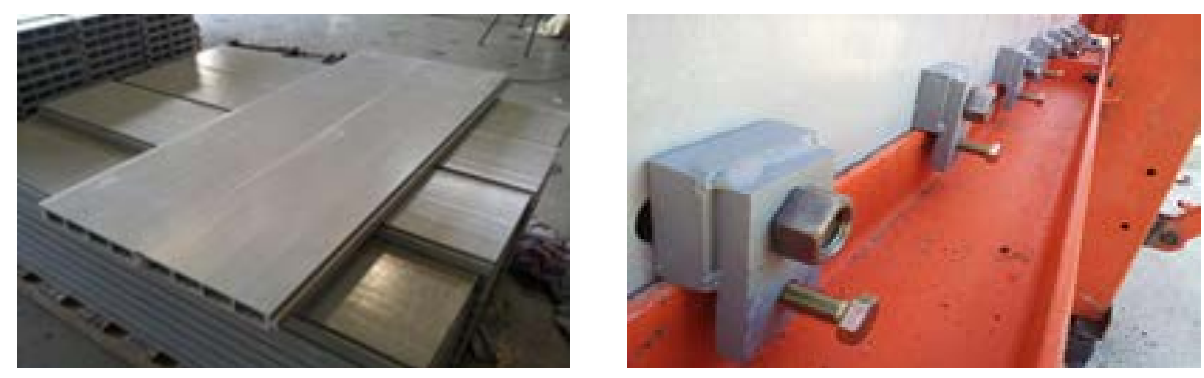

Figure 4. Modular lightweight GFRP form.

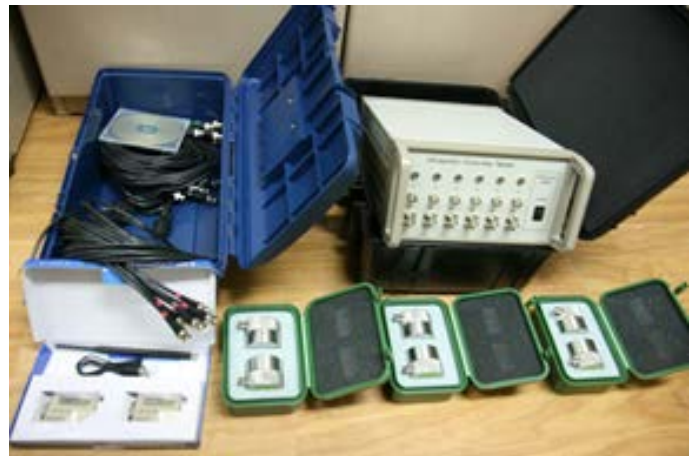

Figure 5. Ultrasonic wave module.

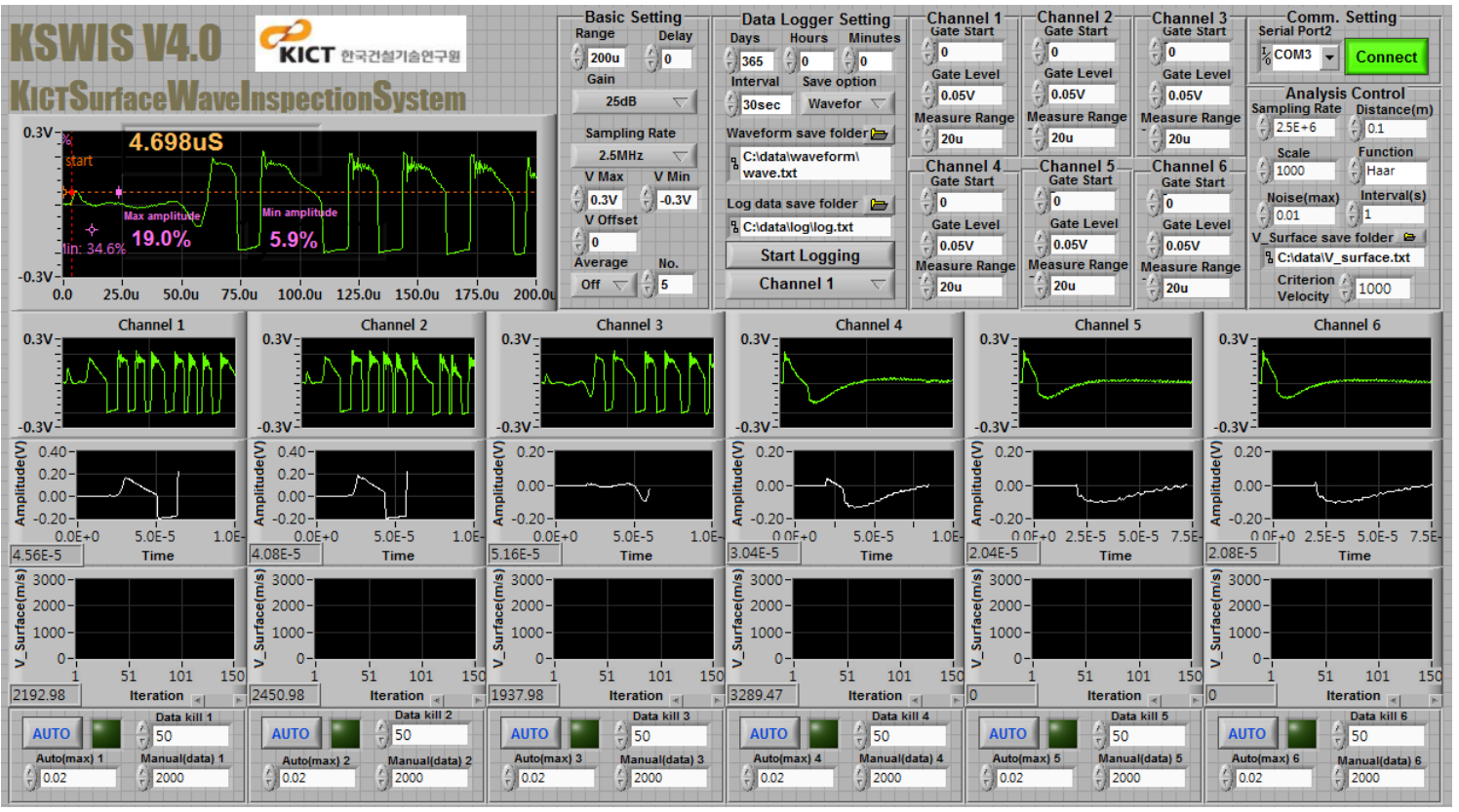

Figure 6. Surface wave inspection system.

time during which the technician can rotate the spindles. If the spindles cannot be rotated within this time, the tapering of the slip form system cannot be done. Recalling that, to date, the spindle rotation task was conducted individually by manpower, the adoption of an electro-motor eases the task and allows individual as well as simultaneous control (Figure 7). The spindle rotation task is shortened through individual or simultaneous control of the spindles. This solution improves effectively the efficiency of the slip form tapering task. The use of an electro-motor enables to realize accurate spindle rotation angle and results in the possibility to achieve more accurate configuration control (Figure 8). 


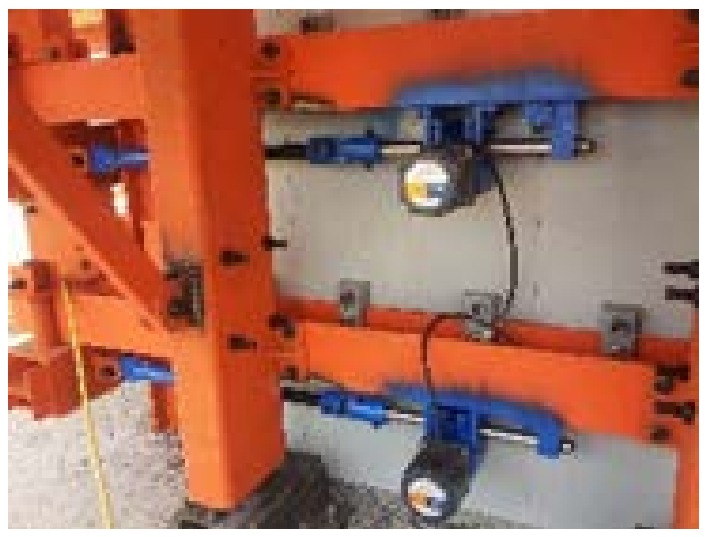

Figure 7. Electromotive spindle.

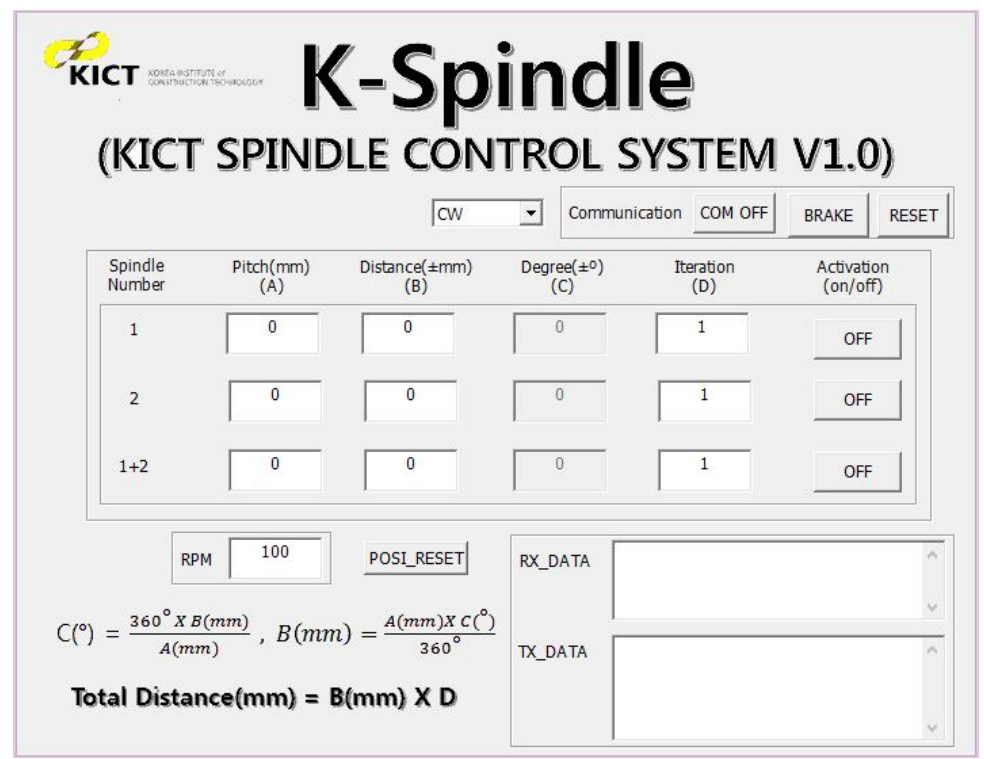

Figure 8. Spindle control program.

\subsection{Erection Accuracy Control}

In order to realize the accurate erection of the concrete pylon, the need is to prepare a database collecting the observation related to the environmental factors around the bridge site together with the corresponding responses of the structure. Especially, during the slip forming of high pylon, the eccentric loading caused by the reinforcement waiting for assemblage at the top of the slip form may deform the form, and differential displacement of the form may occur due to partial lifting. Accordingly, this research developed the KICT Integrated Configuration control System (KICS) for the shape control and position correction of the slip form so as to minimize the effects of climate and 3-dimensional tapered cross section (Figure 9). To that goal, GPS and inclinometer were applied for all-weather measurement, and research was done on data acquisition and processing methods to secure the accuracy. The optimal position and most suitable attachment method inside the slip form were devised to minimize the effects of the wind, vibration and tower crane. Moreover, the traditional plumb laser measuring visually the verticality was improved by attaching a wireless camera so as to monitor the verticality of the pylon in real time from a remote control room (Figure 10) [6].

\section{Open Validation Tests}

A series of 3 mockup tests were conducted to test the performances of the core technologies developed in this research (Figure 11). The first mockup test verified the performance of the wireless hydraulic control system. 


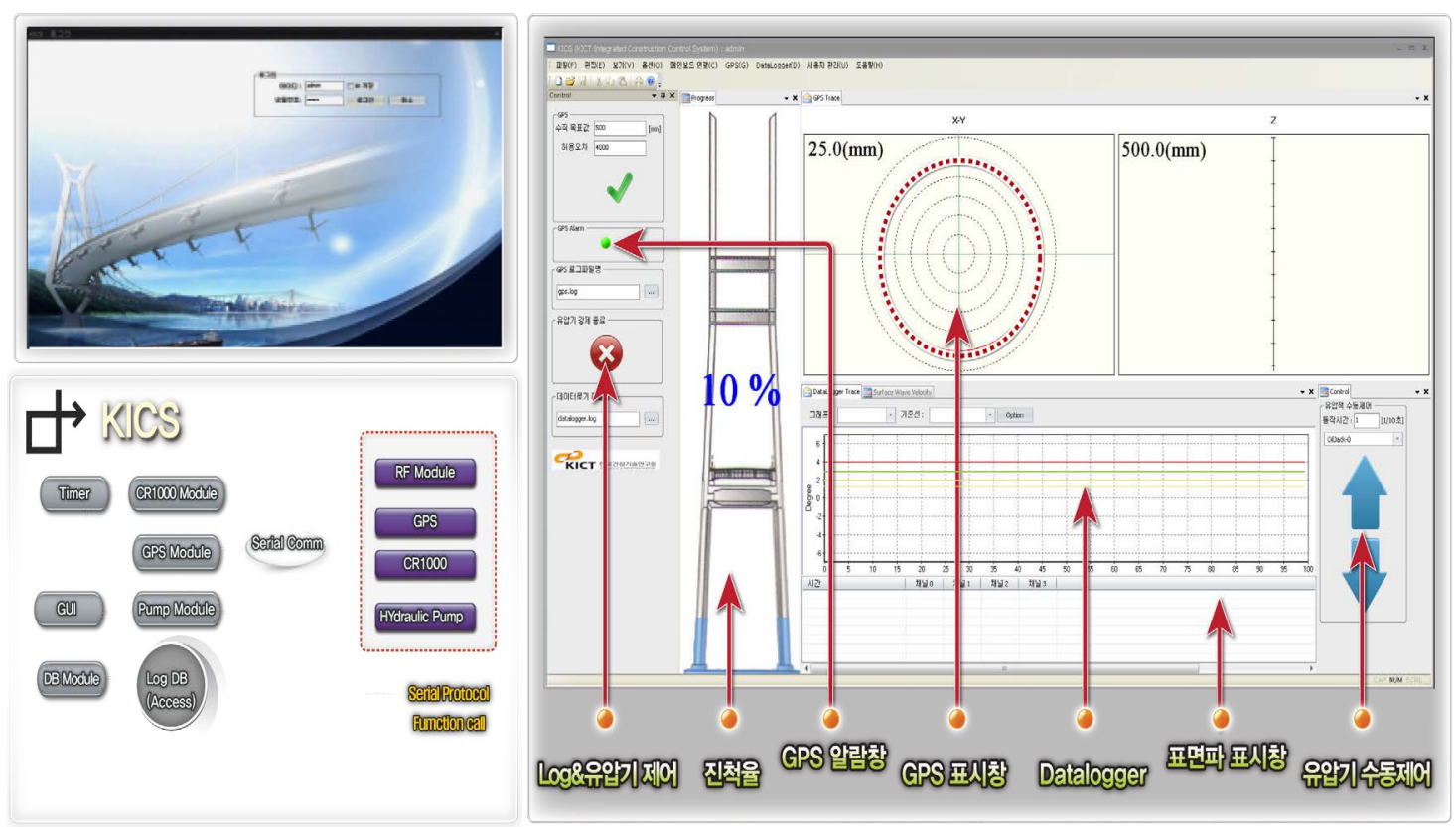

Figure 9. Erection accuracy control system.
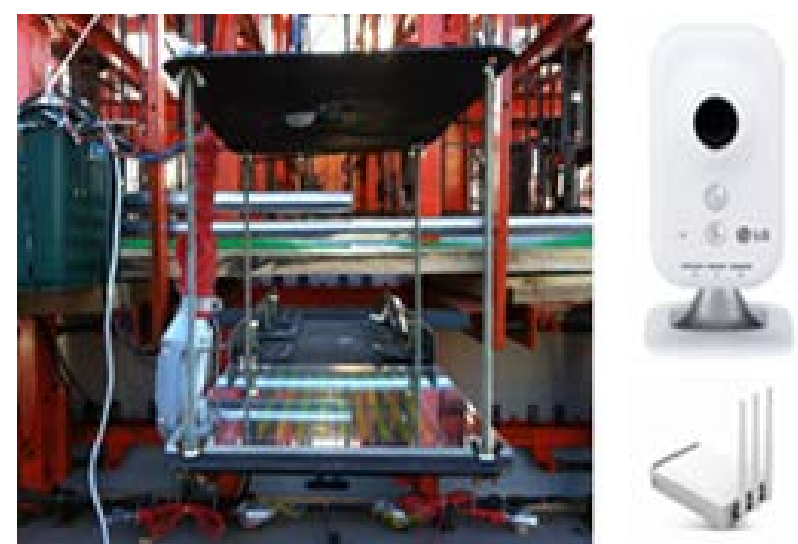

Figure 10. Wireless verticality monitoring.

The second mockup test examined the performance of the surface wave analysis system. And, the third mockup test focused on the performance of the lightweight GFRP panels. Moreover, a series of two public validation tests were conducted using a prototype of the tapered slip form system to verify the performance of the developed system.

The first public validation test intended to verify the performance of the developed core technologies. The test constructed a tapered concrete pylon of $10 \mathrm{~m}$ exhibiting a rectangular cross section varying from $4.0 \mathrm{~m} \times 4.0 \mathrm{~m}$ at the base to $3.77 \mathrm{~m} \times 3.6 \mathrm{~m}$ at the top (Figure 12).

In the second public validation test, the erection was executed considering the actual conditions of a pylon site including the installation of the cable anchorage during construction. The two legs of the pylon were erected simultaneously using a latticed girder. The test constructed the two legs of a tapered concrete pylon exhibiting rectangular cross sections with dimensions varying from $4.0 \mathrm{~m} \times 4.0 \mathrm{~m}$ at the base to $4.0 \mathrm{~m} \times 3.6 \mathrm{~m}$ at the top (Figure 13).

Figure 14 shows the variation of the curing temperatures according to form materials (steel vs. GFRP) in the curing temperature measurement test which was conducted before the second public validation test. Figure 14 shows that the insulating capacity of GFRP is superior to that of steel. This property of GFRP can shorten the construction period especially in winter. 


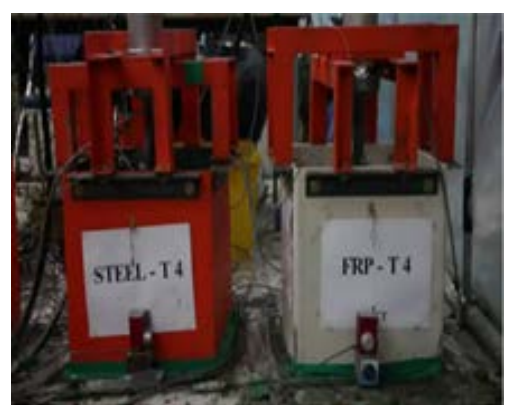

(a)

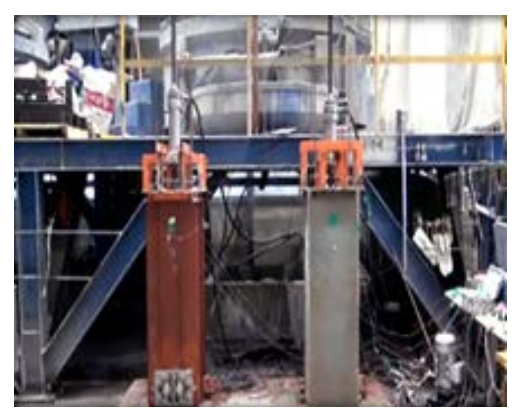

(b)

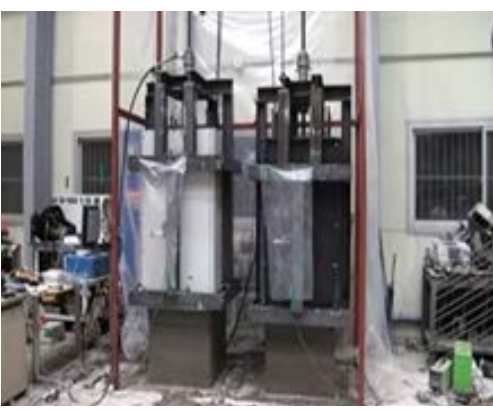

(c)

Figure 11. Mockup tests. (a) First mockup test; (b) Second mockup test; (c) Third mockup test.

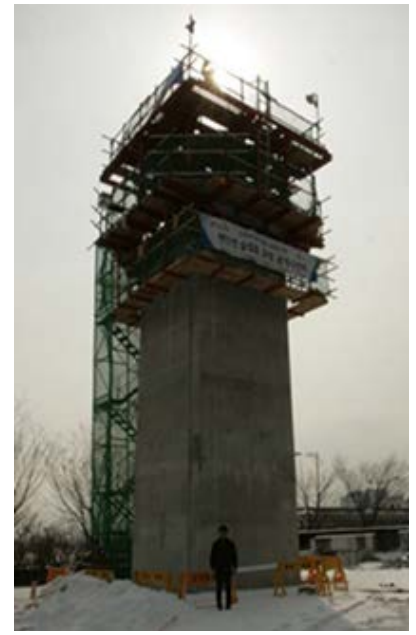

Figure 12. First public validation test.

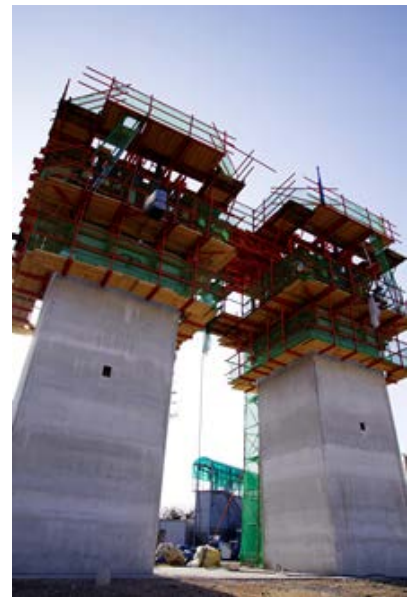

Figure 13. Second public validation test.

Figure 15 shows the surface wave velocity measured by KSWIS (Figure 6) during the second public validation test. In Figure 15, it can be observed that the surface wave velocity experienced sudden decrease. This sudden decrease can be attributed to the climbing of the slip form, which led the surface wave velocity measurement device attached to the slip form to measure the surface wave velocity of concrete that was not cured enough. This result means that the exact climbing time of the slip form system can be effectively determined using KSWIS. 


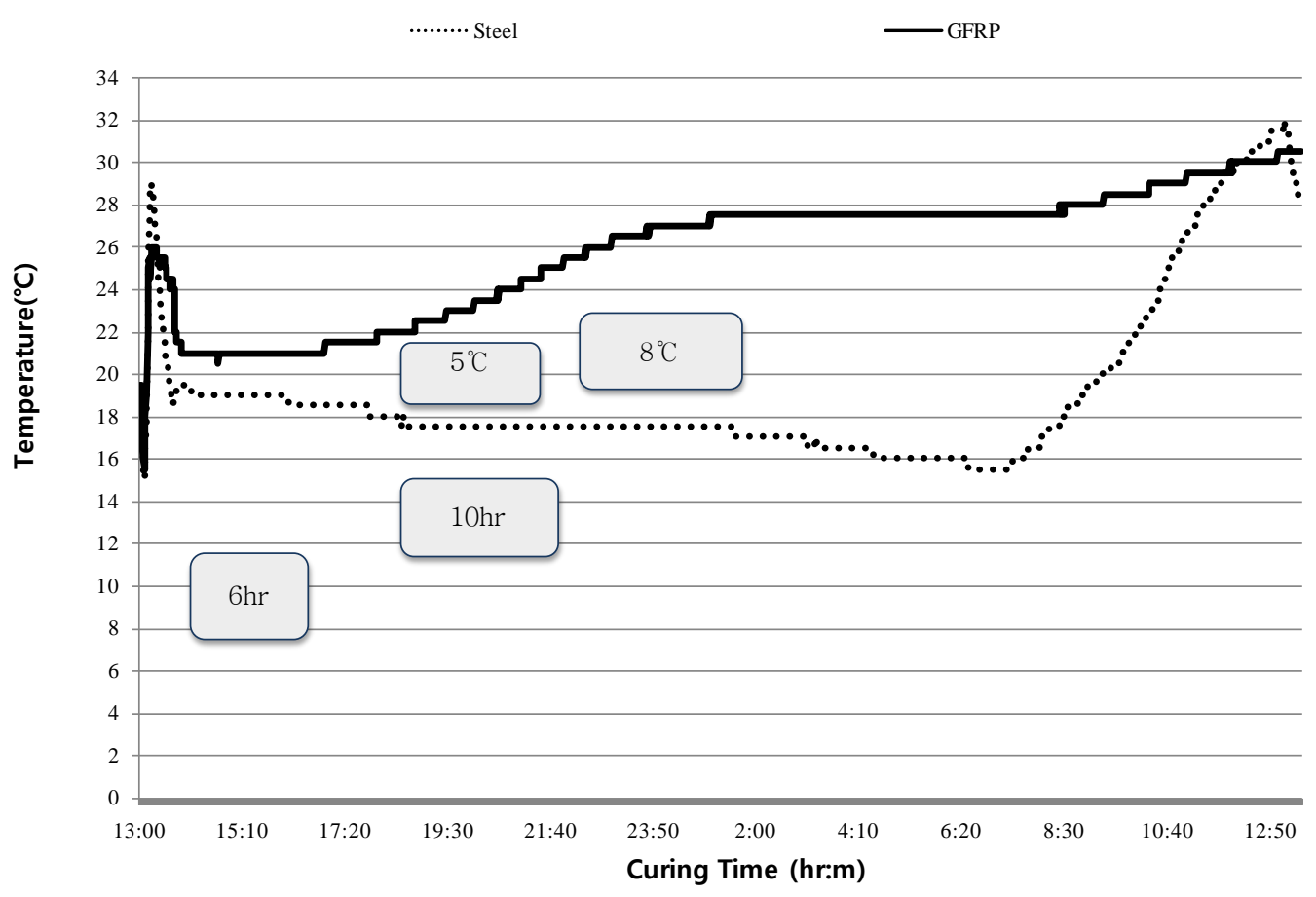

Figure 14. Curing temperature according to form materials.

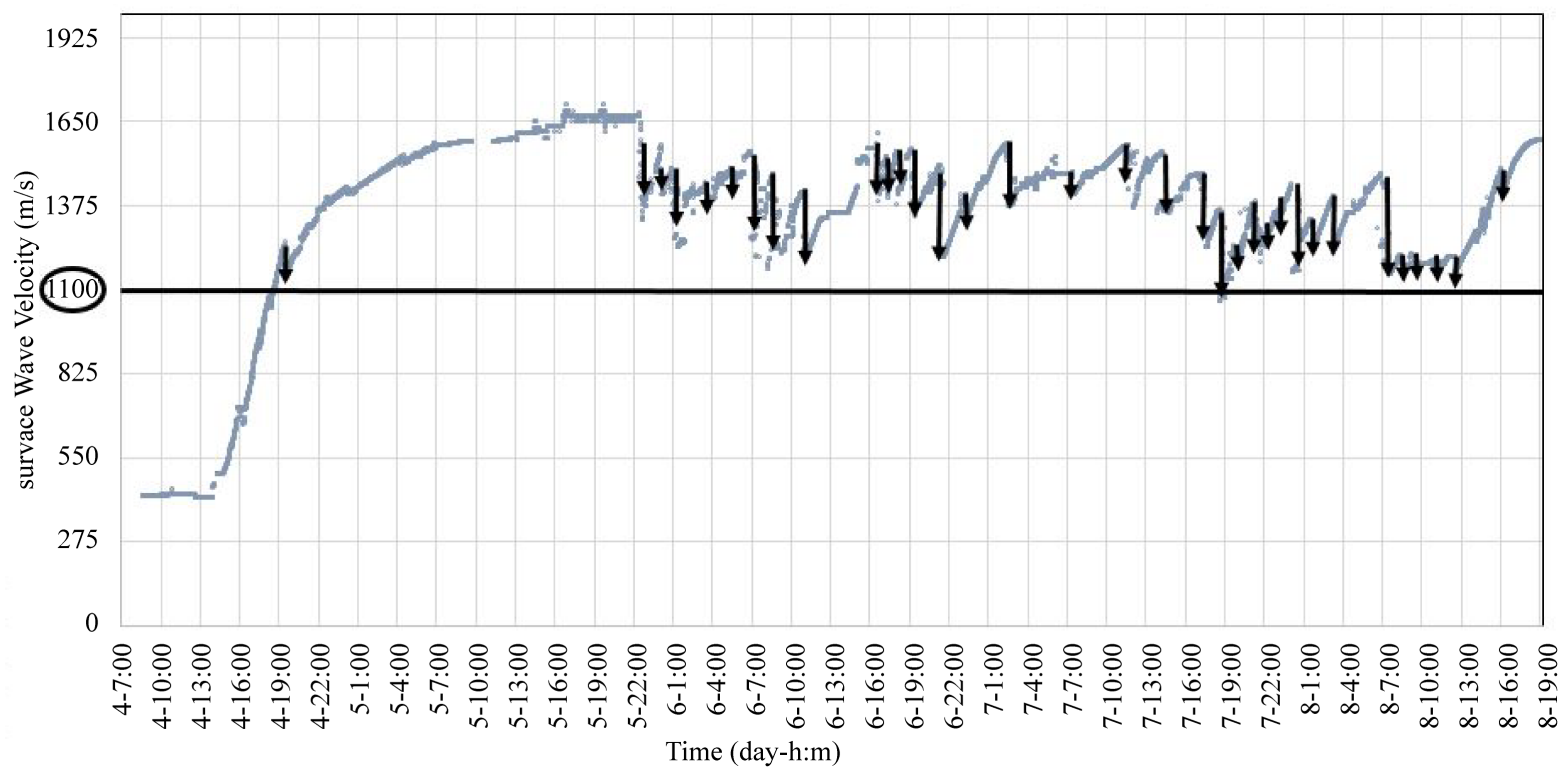

Figure 15. Slip-up of the slip form system according to the surface wave velocity.

Figure 16 compares the values of the height measured during the second public validation test by the GPS, tape ruler, laser distance meter and total station. The application of the KICS using RTK-GPS enabled to conduct successfully the configuration management during the slip forming of the two legs of a 10 m-high concrete pylon with tapered section using the K-slip form. The two public validation tests offered the opportunity to apply all the technologies developed in this research including design technology, lightweight technology, automation technology and erection accuracy control technology. The test results demonstrated that the tapered slip form system developed in this research could successfully achieve the erection of tapered concrete pylons securing outstanding quality of concrete with remarkable efficiency and rapidity. 


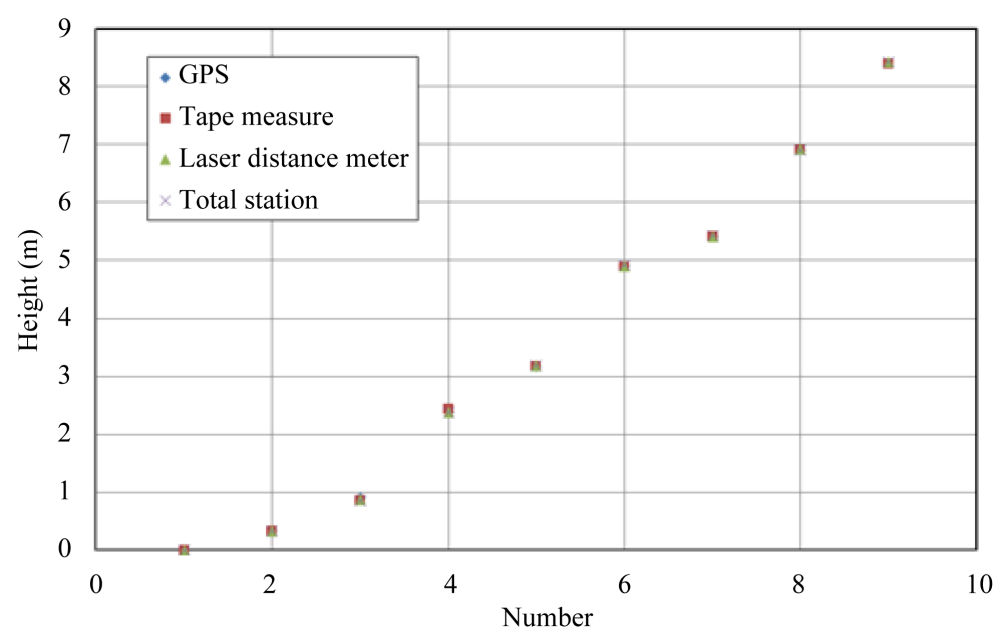

Figure 16. Comparison of height measured by GPS, tape measure, laser distance meter and total station.

\section{Conclusions}

A series of public validation tests demonstrated that the tapered concrete pylon could be successfully erected by means of the slip form system developed in this study. By integrating the latest IT technology for the design, automated operation and configuration control, the developed tapered slip form system secures outstanding quality of concrete and faster construction than foreign technology. This research offered the opportunity to acquire design technology for the tapered section of the slip form system as well as the management technology for erection accuracy. GFRP panels were applied for the first time in the world. The technique determining the slip-up time of the slip form using surface wave, the wireless hydraulic control technique and the electromotive spindle control technique were developed to realize the automated operation technology of the system.

Requests for license agreement and new excellent technology are currently introduced. In the future, the efficiency of the tapered slip form system in adapting to various site conditions will be demonstrated through its application in real bridge construction sites so as to achieve the self-reliant and complete erection of the pylons of super long-span bridges. Apart from bridge's pylons, this tapered slip form system technology will find application for the construction of wider types of elevated structure projects like the chimneys of thermoelectric power plants and wind power towers.

Since the fundamental technologies related to this innovative tapered slip form system have been acquired, the Korean construction industry can now secure an unrivaled competitiveness in the foreign super long-span bridge market, which will provide a platform for winning overseas bridge projects.

\section{Acknowledgements}

This paper was supported by the "Development of Accelerated Construction Technologies for High Pylons" project of the Super Long-Span Bridge R\&D Program. The authors express their gratitude for the support.

\section{References}

[1] Kim, H.S., Kim Y.J., Chin, W.J. and Yoon H. (2013) Development of Highly Efficient Construction Technologies for Super Long Span Bridge. Engineering, 5, 629-636. http://dx.doi.org/10.4236/eng.2013.58075

[2] Yoon, H., Chin, W.J., Kim, H.S. and Kim, Y.J. (2013) Development of an Efficient Tapered Slip-form System Applying BIM Technology. Engineering, 5, 693-699. http://dx.doi.org/10.4236/eng.2013.59082

[3] Kim, H. (2012) Mechanical Characteristics of GFRP Slip Form for In-Situ Application. Ph.D. Thesis, Hanyang University, Seoul.

[4] Kim, H.S., Kim Y.J., Chin, W.J. and Yoon H. (2013) Determination of the Slip-Up Time for Slip Form System Using Surface Wave Velocity. Proceedings of ASME 2013 International Mechanical Engineering Congress and Exposition, 15-21 November 2013, 15. 
[5] Shin, S.W., Yun, C.B., Popovics, J.S. and Kim J.H. (2007) Improved Rayleigh Wave Velocity Measurement for Nondestructive Early-Age Concrete Monitoring. Research in Nondestructive Evaluation, 18, 45-68. http://dx.doi.org/10.1080/09349840601128762

[6] Chin, W.J., Kim, Y.J., Kim, H.S., Yoon, H., Kim, B.S. and Sim J.S. (2013) Innovative Slip Form Method for the Construction of Tapered Concrete Pylon of Long-Span Cable Bridge. 36th IABSE Symposium, Kolkata, 24-27 September 2013, 442-443. 
Scientific Research Publishing (SCIRP) is one of the largest Open Access journal publishers. It is currently publishing more than 200 open access, online, peer-reviewed journals covering a wide range of academic disciplines. SCIRP serves the worldwide academic communities and contributes to the progress and application of science with its publication.

Other selected journals from SCIRP are listed as below. Submit your manuscript to us via either submit@scirp.org or Online Submission Portal.
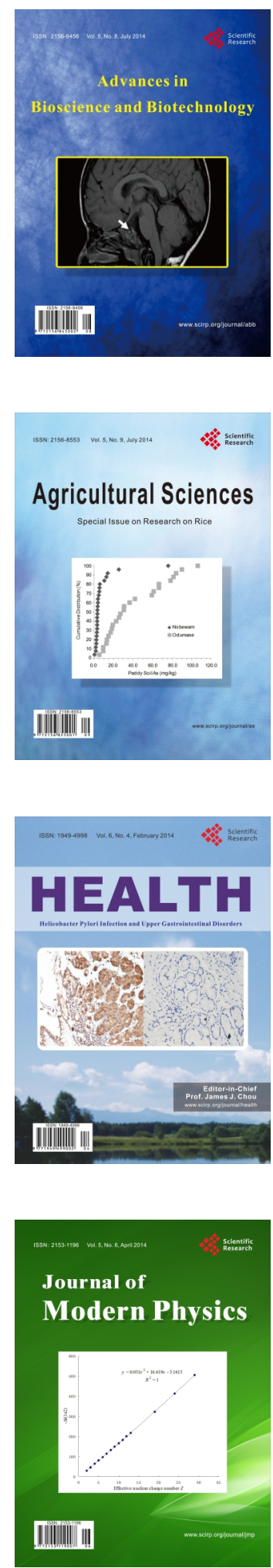
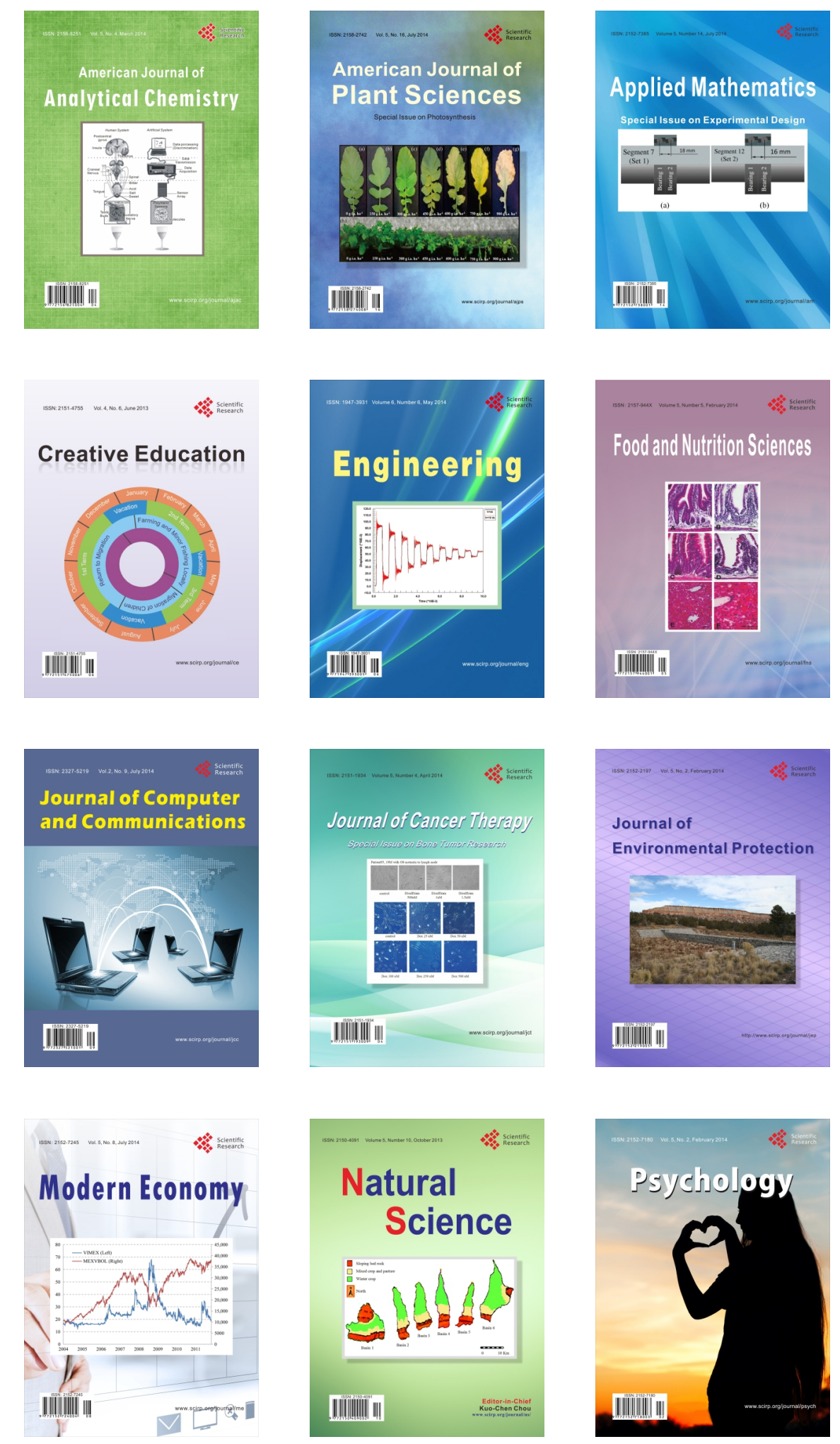